\title{
Acceso al derecho de asilo de los niños, niñas y adolescentes no acompañados en México
}

\author{
Sergio A. Rea Granados \\ Universidad de Chile
}

\begin{abstract}
Resumen
Este artículo tiene la finalidad a estudiar los diferentes problemas, realidades y retos que enfrenta la niñez refugiada no acompañada en México para acceder al procedimiento de asilo en México. Sobre todo, cuando el fenómeno de la movilidad humana ha tenido gran relevancia en esta región de las Américas debido a las políticas actuales migratorias, las cuales tienden a darle mayor prioridad al tema de seguridad, que a los derechos humanos de los niños, niñas y adolescentes (NNA) con indicios de desprotección internacional. Al respecto, se utilizará el método sistemático y de revisión bibliográfica, para analizar el problema del acceso al procedimiento de asilo de la niñez refugiada en México y, los retos que enfrentan en cuanto a sus derechos humanos. Esta propuesta toma como referencia los planteamientos abordados desde la perspectiva del derecho internacional de los derechos humanos y del derecho de los refugiados.
\end{abstract}

Palabras claves: Niñez refugiada no acompañada, derecho al acceso al procedimiento de asilo, condición de vulnerabilidad, derechos de los refugiados y derechos de la niñez.

\section{Access to asylum process to unaccompanied children in Mexico}

\begin{abstract}
The purpose of this article is to study the different problems, realities and challenges faced by unaccompanied refugee children in Mexico to access the asylum procedure in Mexico. Above all, when the phenomenon of human mobility has had great relevance in this region of the Americas due to current migration policies, which tend to give higher priority to the issue of security, than to the human rights of children and adolescents (children) with signs of international lack of protection. In this regard, the systematic and bibliographic review method will be used to analyze the problem of access to the asylum procedure for refugee children in Mexico and the challenges they face in terms of their human rights. This proposal takes as a reference the approaches approached from the perspective of international human rights law and refugee law.
\end{abstract}

Keywords: Unaccompanied refugee children, the right to have access to the asylum process, vulnerability, refugee rights and rights of children.

Artículo recibido el 4 de marzo de 2019 y aprobado el 11 de marzo de 2020. 


\section{INTRODUCCIÓN}

$\mathrm{E}$ $\mathrm{n}$ la región de Centroamérica y Norteamérica se ha incrementado el número de personas que se suman al fenómeno de la movilidad humana. Lo anterior, ha sido un reto considerable para los Estados, no solo porque amenazan su prerrogativa soberana de determinar qué ciudadanos no nacionales pueden entrar a su territorio y bajo qué condiciones, sino también - y mucho más importante- porque las personas que participan en esos movimientos son más propensas a sufrir privaciones, discriminación y violaciones a sus derechos humanos; y, por tal razón, requieren consideraciones especiales e individualizadas. ${ }^{1}$

México, debido a su proximidad con Estados Unidos, es uno de los lugares en que el fenómeno de la movilidad humana reviste mayor complejidad por ser considerado uno de los corredores migratorios de mayor flujo mundial debido a su frontera sur con Centroamérica y al norte con Estados Unidos. ${ }^{2}$ En efecto, ya el simple hecho de contar con una extensa frontera con Estados Unidos hace a México un lugar de origen, tránsito y destino de migrantes; y, últimamente en lo que atañe al objeto de nuestra investigación, el centro de una ola de niños, niñas y adolescentes (NNA) no acompañados con indicios de desprotección internacional. Por lo tanto, la dimensión que tiene este fenómeno hace que México sea, dentro del continente americano, el país que refleja de forma más clara el carácter diverso de las diferentes facetas de la migración internacional. ${ }^{3}$ Por lo tanto, los problemas migratorios se agravan en Estados Unidos, donde las políticas se centran en el control de la migración y seguridad, más allá de cumplir con las obligaciones internacionales. Cabe señalar que la movilidad de mexicanos hacia Estados Unidos ocupó durante muchos años el principal y único tema de los estudios de la migración, sin embargo, actualmente ha cobrado especial importancia la movilidad humana de personas extranjeras

1 Organización Internacional para Las Migraciones (OM), Migración Irregular y los flujos Migratotios Mixtos: Enfoque de la OIM, MC/INF/297, 2009, p.1.

2 The World Bank. Migration and Remittances Factbook 2011, Washington D, C., 2011, p. 5

3 Comisión IDH. Derechos humanos de los migrantes y otras personas en el contexto de la movilidad humana en México, OEA/Ser. L/V/II, Washington, D.C., 2013, p. 2. 
dentro del territorio mexicano, entre ellos NNA no acompañados. Esto debido a que México no ha sido sólo un país de origen sino también de tránsito y destino de flujos migratorios internacionales.

En este sentido, el interés de este artículo consiste en estudiar los diferentes problemas, realidades y retos que enfrentan los NNA no acompañados para que puedan acceder al procedimiento de asilo en México.

Por tal razón, nuestra hipótesis sería que dentro de los flujos migratorios mixtos los NNA no acompañados tienen acceso a los procedimientos de asilo en México sin impedimento alguno.

\section{Contexto}

Actualmente, la política migratoria de Estados Unidos está mayormente orientada a limitar los derechos de las personas en movilidad, ya que está orientada a la seguridad nacional. Además de la falta de soluciones viables y prácticas que contribuyan al respeto de las obligaciones internacionales en materia de derechos humanos y de ayuda humanitaria a favor de las personas solicitantes de la condición de refugiado y refugiada. Por tal razón, éstas son limitadas, insuficientes e inadecuadas para resolver el gran problema de las violaciones a los derechos humanos y muy particularmente de los NNA no acompañados.

Algunas de las razones por la que Estados Unidos adopta esta política restrictiva son: en primer lugar, la campaña política anti migratoria del actual presidente; en segundo lugar, que los NNA no acompañados son percibidos con la idea tradicional de que atentan contra la soberanía nacional, ya que la mayoría de estas personas cruzan la frontera de manera irregular. En tercer lugar, por el temor de aceptar y de adoptar disposiciones legales y políticas públicas orientadas a entender, aceptar, integrar y regular este fenómeno social. En cuarto lugar, por los discursos de odio y discriminación por la política migratoria actual de Estados Unidos.

Debido a esta situación, México se ha convertido un país receptor de personas que requieren protección internacional, incluyendo a los NNA no acompañados, principalmente los que provienen de América Central, quienes al no contar con la compañía de un adulto y al carecer de documentos de identidad prefieren permanecer en el anonimato. Hecho que los sitúan en vulnerabilidad en cuanto a sus principales 
derechos humanos, así como también a los mecanismos sociales de integración. ${ }^{4}$

Cabe recordar que los NNA no acompañados son aquéllos que están separados de ambos padres y otros parientes y no están al cuidado de un adulto al que, por ley o costumbre, incumbe esa responsabilidad. ${ }^{5}$ Ahora bien, muchos de ellos tienen indicios de protección internacional, es decir, que aún no existe una intervención especializada que declare que se requiere protección internacional, sino, existe la presunción que el NNA reúne los elementos de la definición de refugiado.

Ahora bien, en el caso de los NNA no acompañados, debido al contexto que hemos mencionado los indicios de protección internacional se debe a que, generalmente, son víctimas en sus países de origen por ataques militares y armados, son reclutados por las fuerzas armadas o por otros grupos, utilizados como mano de obra, secuestrados, son adoptados de manera irregular, sufren abusos físicos y/o sexuales, incluida la tortura, son explotados, discriminados, abandonados, descuidados y son sujetos de detención arbitraria. ${ }^{6}$ En el caso del Triángulo Norte de América Central, es decir, de Honduras, Guatemala y El Salvador, el Alto Comisionado de las Naciones Unidas para los Refugiados (ACNUR) ha señalado que, uno de los mayores riesgos en los NNA que se encuentran en zonas donde operan los grupos criminales, entre ellos las pandillas, es que son reclutados forzosamente, intimidados, o bien, amenazados, por lo tanto, esta población podría requerir protección internacional. ${ }^{7}$

Ahora bien, como lo señalamos muchos de estos NNA no acompañados utilizan las migraciones mixtas para viajar de un estado a otro y, por lo tanto, suelen confundirse con aquellos migrantes que no entran en la definición de refugiado de acuerdo con la Convención

4 Human Rights Watch, Puertas cerradas: el fracaso de México en la protección de niños refugiados y migrantes de América Central, 31 de marzo, 2016. En línea: https://www. hrw.org/es/report/2016/03/31/puertas-cerradas/el-fracaso-de-mexico-en-la-proteccion-de-ninos-refugiados-y

5 Comité de los Derechos del Niño, Observación General No 6, Trato de los menores no acompañados y separados de su familia fuera de su país de origen, CRC/GC/2005/6, parra. 7.

6 ACNUR, (1994). Los niños refugiados: directrices sobre protección y cuidado, Ginebra, ACNUR, 1994, p. 85.

7 ACNUR, (2016a). Directrices de elegibilidad para la evaluación de las necesidades de protección internacional de los solicitantes de asilo procedentes de Honduras, ACNUR, HCR/ EG/HND/16/3, 2016, p. 60.

ACNUR, (2016b). Directrices de elegibilidad para la evaluación de las necesidades de protección internacional de los solicitantes de asilo procedentes de El Salvador, ACNUR, HCR/EG/SLV/16/1, 2016, p. 38 
de 1951 sobre el Estatuto de los Refugiados, así como la Declaración de Cartagena de 1984.

Siguiendo con esta orden de ideas, "uno de los grandes retos que enfrenta esta población en situación de vulnerabilidad es que dentro de las migraciones mixtas resulta difícil identificar a los solicitantes de asilo y aquellas personas que viajan por otros motivos". ${ }^{8}$ La diferencia entre migrantes y refugiados se debe no sólo a la cuestión legal, sino que los refugiados requieren mayor protección, ya que su vida, libertad y seguridad se han visto amenazadas por ciertos motivos y, por lo tanto, no pueden por ninguna causa regresar a su país de origen. Mientras tanto, los migrantes, aunque también se encuentran en una situación vulnerable en cuanto a la violación de sus derechos humanos, si tienen la posibilidad de regresar a su país de origen, ya que no salieron de él por la fuerza.

Debido a esta diferenciación, todas las personas refugiadas, incluyendo a los NNA no acompañados que requieren protección internacional tienen derechos específicos como la no devolución, la no sanción por entrada irregular, entre otros. Por tal razón, es sumamente importante que este grupo poblacional tenga acceso efectivo al procedimiento de asilo para ejercer los derechos antes mencionados.

\section{LOS DERECHOS DE LOS NNA NO ACOMPAÑADOS CON INDICIOS DE DESPROTECCIÓN INTERNACIONAL EN MÉXICO}

Primeramente, es importante señalar que, debido al contexto antes mencionado, dos de los principales campos del derecho internacional que han cobrado mayor importancia en la protección de los derechos de los NNA no acompañados y con indicios de protección internacional son: por un lado, el Derecho Internacional de los Derechos Humanos (en adelante "DIDH") y, por el otro, el Derecho Internacional de los Refugiados (en adelante "DIR").

México ha ratificado los principales instrumentos internacionales que protegen a los NNA no acompañados y que requieren protección internacional. Por ejemplo, la Convención Americana de Derechos Humanos, ratificado el 3 de febrero de 1981; Convención de 1951 sobre el Estatuto de los Refugiados, ratificado el 25 de agosto de 2000;

8 Rea Granados, Sergio Alejandro, (2016a). Retos Actuales en la Implementación de la Ley sobre Refugiados y Protección Complementaria en México: Identificación, Admisión y Acceso al Procedimiento de Asilo, Anuario Mexicano de Derecho Internacional, (XVI), México, Instituto de Investigaciones Jurídicas, UNAM, 2016, p. 9. 
Protocolo de 1967 del Estatuto de los Refugiados, ratificado el 25 de agosto de 2000; Pacto Internacional de Derechos Civiles y Políticos, ratificado el 23 de marzo de 1981; Convención sobre Derechos del Niño, ratificado el 25 de enero de 1991.

Debido a la importancia de brindar protección a los NNA en 1989 se promulgó la Convención sobre Derechos del Niño (en adelante “CDN"), ${ }^{9}$ la cual se erige como una síntesis de las normas provenientes de instrumentos de derechos humanos de carácter general con principios y derechos propios vinculados a los derechos de la infancia. La CDN concibe a los NNA no sólo como sujetos de medidas de protección y asistencia, sino como titulares de derechos propios y como actores de su propia vida; y, por lo tanto, con la capacidad y el deber de participar en los asuntos que les afectan.

En efecto, la CDN incorpora cuatro principios y derechos específicos: el derecho intrínseco a la vida, supervivencia y desarrollo; a la participación; a la no discriminación y el principio de interés superior de la niñez (en adelante "ISN"). Además de estos cuatro derechos y principios, la CDN establece otros derechos fundamentales que incluyen, inter alia, la necesidad de proteger a la niñez de abuso, de la explotación, del trato negligente y aquéllos que lo protegen de la persecución.

A partir de la Convención sobre Derechos del Niño se han diseñado nuevas medidas para hacer frente a la violación de derechos humanos de los NNA en diversas partes del mundo, incluyendo a México quien también es parte de este instrumento internacional. Sin embargo, lamentablemente, en el caso concreto de los NNA no acompañados y con indicios de protección internacional sus derechos y principios específicos reconocidos por el DIR no son tomados en cuenta al no acceder al procedimiento de asilo que les reconozca la condición de refugiado para que puedan ejercer eficazmente estos derechos, tales como, el derecho a la no devolución ${ }^{10}$ y la no sanción por entrada irregular, ${ }^{11}$ entre otros.

Por lo tanto, desde esta perspectiva y bajo el principio de progresividad del DIDH:

9 Aprobada y abierta a firma y ratificación por la Asamblea General en su resolución 44/25, de 20 de noviembre de 1989. Entrada en vigor el 2 de septiembre de 1990.

10 Convención de 1951 sobre el Estatuto de los Refugiados. Artículo 33. Prohibición de expulsión y de devolución ("refoulement").

11 Convención de 1951 sobre el Estatuto de los Refugiados. Artículo 31. 
los Estados deben de adoptar las medidas apropiadas - incluyendo las de carácter legislativo, administrativo y judicial que sean necesarias - para adecuar el ordenamiento interno al espíritu, sentido y alcance de las normas contenidas en los tratados internacionales (Miguel Carbonell y Pedro Salazar, 2011: 78).

Al respecto, México cuenta con una amplia legislación en estas materias, Ley de Migración, Ley sobre Refugiados, Protección Complementaria y Asilo Político, Ley General de los Derechos de Niñas, Niños y Adolescentes, Ley de Nacionalidad, entre otros.

Sin embargo, no basta con contar con el ordenamiento legislativo, sino también, implementar e interpretar correctamente la ley, así como generar nuevas e incluyentes políticas públicas que ayuden a superar los retos que enfrentan los NNA no acompañados con indicios de protección internacional para que accedan al procedimiento de asilo $\mathrm{y}$, de tal forma, sean reconocidos como refugiados para que puedan ejercer sus derechos relacionados a la figura del asilo.

A pesar de la existencia de normas internacionales a favor de la niñez no acompañada, la realidad demuestra que esta población continúa estando en una situación vulnerable a cada uno de los desafíos antes mencionados.

\section{ACCESO AL PROCEDimiento de ASILO de NNA No ACOMPAÑADOS EN MÉXICO}

Aunque México no es el primer objetivo de los NNA no acompañados provenientes de América Central, lo cierto es que, debido a las actuales políticas migratorias restrictivas en Estados Unidos, muchos de ellos comienzan a quedarse o mantenerse temporalmente en México. Sobre este asunto, el ACNUR ha señalado que "existe un número creciente de solicitantes de asilo en México, sobre todo niños no acompañados, provenientes de El Salvador, Honduras y Guatemala". ${ }^{12}$

Sin embargo, muchos de estos NNA no acompañados se enfrentan a un sinfín de retos en México, uno de ellos es contar con el acceso al procedimiento de asilo en México. Lo anterior, debido a diversos factores que obstaculizan, entorpece, o impiden tener acceso efectivo al derecho a que se les reconozca su condición de refugiado.

Uno de los principales problemas es que muchos de los NNA no acompañados no cuentan con documentos de identidad ni de viaje $\mathrm{y}$,

12 UNHCR. Children on the Run: Unaccompanied Children Leaving Central America and Mexico and the need for International Protection, 2014, pp. 6-8. 
debido a ello, muchos de ellos por temor a no contar con ellos deciden no informarse de cómo acceder al procedimiento de asilo en México. Desafortunadamente, tras no contar con información sobre este derecho, los sitúa en una situación de vulnerabilidad, ya que al ser NNA no acompañados requieren una atención especial diferenciada para satisfacer sus necesidades básicas. ${ }^{13}$

Además, la falta de documentación agrava su situación, ya que la falta de identidad y veracidad de los datos proporcionados por esta población dificulta que sean localizados lo antes posible a sus progenitores o a sus familiares. Además, a menudo corren el riesgo de detención, incluso la misma podría ser muy prolongada o indefinida por carecer de documentos de identificación.

En el mismo sentido, para evitar la detención por falta de documentos, muchos de los NNA no acompañados deciden permanecer o transitar en la clandestinidad para no ser localizados ni identificados por los agentes de migración.

Además, este hecho desafortunadamente los convierte en sujetos potenciales de servíctimas de trata y de tráfico. Por lo tanto, nuevamente estamos en un problema generado por no acceder al procedimiento de asilo en México, el cual no resuelve todos sus problemas, más bien, ayuda a que sus derechos sean restituidos y protegidos.

Cabe resaltar que, en México, existen los Oficiales de Protección a la Infancia (OPI), quienes son agentes federales de migración cuyo principal objetivo es garantizar el respeto a los derechos humanos de los NNA migrantes y refugiados. Autoridades migratorias que tienen las facultades legales y la capacitación técnica de brindar información, identificar a posibles NNA no acompañados y con necesidades de protección y, ellos serían quienes pueden canalizar a los NNA no acompañados al procedimiento de asilo ante la Comisión Mexicana de Ayuda a Refugiados (COMAR), o bien, a los Sistemas Nacionales, Estatales o Municipales para el Desarrollo Integral de la Familia (DIF).

Los OPI tienen la responsabilidad de canalizar a todos los NNA no acompañados que identifiquen dentro de los flujos migratorios mixtos, incluyendo aquéllos que requieran protección internacional, hacia los sistemas de protección de la infancia para la restitución de sus derechos.

13 Ortega Velázquez, Elisa. "Los niños migrantes irregulares y sus derechos humanos en la práctica europea y americana: entre el control y la protección, Boletín mexicano de derecho comparado", 48(142), 2015. 
En el caso particular, los OPI tendrían que canalizar a los NNA no acompañados al DIF, sea nacional, estatal o municipal, quienes serán los responsables jurídicamente de brindar acompañamiento, asesorías y representación legal. ${ }^{14}$ Ahora bien, en el caso del acceso al procedimiento de asilo, el DIF, por medio de la Procuraduría de Protección de Niñas, Niños y Adolescentes, sea federal, estatal o municipal deberán de brindar información clara, sencilla y comprensible a los NNA no acompañados sobre el procedimiento de asilo. Por lo tanto, la información de este procedimiento deberá ser mediante un lenguaje que respete su edad, desarrollo evolutivo y cognoscitivo y grado de madurez.

Además, los DIF, federal, estatal o municipal deberán garantizar a los NNA no acompañados que puedan presentar una solicitud de reconocimiento de la condición de refugiado, ya sea con representación legal, o bien, por sí solos respetando el principio de la autonomía progresiva. Dicho principio, también se refiere a que el DIF debe acompañar a los NNA no acompañados con personal especializado, quienes deberán de brindar asistencia y protección durante todo el procedimiento de asilo.

Además, es sumamente indispensable que esta autoridad cuente con un enfoque integral, transversal con perspectiva de derechos humanos y de género. ${ }^{15}$ Esto significa que las acciones del DIF deben estar construidas tomando en cuenta las características sociales y culturales que generan desigualdad dentro de la sociedad debido a la forma diferenciada entre niños y niñas. Asimismo, sus acciones deben estar basada en que el NNA disfrute plenamente de todos sus derechos reconocidos no sólo por la Convención sobre Derechos del Niño, sino también de todos los instrumentos internacionales en materia de derechos humanos.

Ahora bien, esta perspectiva también incluye a las autoridades migratorias, quienes deberían de basarse desde la visión de los derechos humanos, incluyendo los derechos de los niños(as) y, no desde la perspectiva de seguridad nacional. Esto es sumamente importante para que también las autoridades migratorias puedan identificar NNA no acompañados con indicios de necesidades de protección.

14 Ley General de Niños, Niñas y Adolescentes. Publicada en el Diario Oficial de la Federación el 20 de junio de 2018.

15 CNDH, (2016), Orientaciones para las Áreas Especializadas en los Derechos de Niñas, Niños y Adolescentes de los Organismos Públicos de Derechos Humanos, CNDH, UNICEF, p. 2-21. 
Ahora bien, lo anterior también implica que el derecho al acceso al asilo pueda garantizar el principio a la no devolución de NNA con necesidades de protección internacional. Parte fundamental de los derechos de los refugiados que señala que una persona solicitante o refugiada no puede regresar al lugar habitual de residencia o su país de origen, ya que en caso contrario su vida, libertad o seguridad estarían en riesgo y, por lo tanto, atentaría en contra de la institución del asilo. ${ }^{16}$

Por eso la importancia que los NNA no acompañados accedan al procedimiento de asilo, ya que su repatriación a sus países de origen de manera expedita se convertiría en una gestión migratoria de peligro que atenta contra los principios medulares del derecho a solicitar asilo.

Esta situación refleja la situación de vulnerabilidad en que se encuentran los NNA no acompañados con indicios de protección internacional, ya que el Estado mexicano comúnmente lleva a cabo el proceso repatriación o internamiento sin haber informado previamente, claramente y correctamente con un lenguaje hacia los NNA sobre el derecho a solicitar asilo y los derechos que vienen implícitos a esta figura, así como el acceso al procedimiento de asilo para que, en caso de ajuste al supuesto, se le reconozca la condición de refugiado.

Debido a este gran problema, los NNA no acompañados que son interceptados por las autoridades migratorias son mayoritariamente repatriados y retornados, incluyendo su aseguramiento en las estaciones migratorias. ${ }^{17}$

Una razón es el alto número de NNA no acompañados que se encuentran en México. Por lo tanto, la autoridad migratoria prefiere no brindar acceso al procedimiento de asilo para no utilizar medios alternativos a la detención, es decir, albergues y otros centros de alojamiento encargados de brindar protección y asistencia a este

16 Convención de 1951 sobre el Estatuto de los Refugiados. Artículo 33. Prohibición de expulsión y de devolución ("refoulement") 1. Ningún Estado Contratante podrá, por expulsión o devolución, poner en modo alguno a un refugiado en las fronteras de los territorios donde su vida o su libertad peligre por causa de su raza, religión, nacionalidad, pertenencia a determinado grupo social, o de sus opiniones políticas. 2. Sin embargo, no podrá invocar los beneficios de la presente disposición el refugiado que sea considerado, por razones fundadas, como un peligro para la seguridad del país donde se encuentra, o que, habiendo sido objeto de una condena definitiva por un delito particularmente grave, constituya una amenaza para la comunidad de tal país.

17 Human Rights Watch, Puertas cerradas: el fracaso de México en la protección de niños refugiados y migrantes de América Central, 31 de marzo, 2016. En línea: https://www. hrw.org/es/report/2016/03/31/puertas-cerradas/el-fracaso-de-mexico-en-la-proteccion-de-ninos-refugiados-y 
grupo poblacional. Al contrario, la autoridad migratoria prefiere la repatriación y el retorno asistido. ${ }^{18}$

También un factor que incide negativamente en el acceso al procedimiento de asilo de los NNA es la corrupción de las fuerzas del orden y los funcionarios de migración. Este problema no solo agrava su situación de vulnerabilidad, sino que, también atenta contra la confianza y la credibilidad de las instituciones de seguridad del Estado, quienes tienen la función de proteger a cualquier persona que se encuentra dentro de su jurisdicción, incluyendo a nuestra población de estudio.

La confianza de las instituciones migratorias es sumamente importante, ya que las NNA no acompañadas al no contar con una persona adulta que pueda defender o proteger sus derechos, la autoridad migratoria funge, en primera instancia, como autoridad encargada de velar porque los derechos de los niños(as) se respeten. Incluso en muchas ocasiones, son ellos quienes tienen que llamar o canalizar los casos de NNA no acompañados a la Procuraduría Federal de Protección a la Infancia para que determinen el interés superior del niño, así como brindarles acceso al procedimiento de asilo.

Además, es importante contextualizar que, debido al desplazamiento forzoso, esta población también se enfrenta al problema de lo desconocido, ya que la mayoría de las NNA no acompañados ignoran a dónde van, ni qué pasará con ellos(as) y, por lo tanto, "viven durante varias semanas en la incertidumbre y cumpliendo las órdenes del agente de migración o peor aún del traficante". ${ }^{19}$

Este hecho, también, provoca un gran reto, ya que los NNA no acompañados, también son fácilmente víctimas de trata de personas, además, es importante resaltar que las niñas enfrentan mayores riesgos a ser víctimas de este delito. ${ }^{20}$

También, las razones de género y edad son variantes que contribuyen a la violación de los derechos humanos como la discriminación. Lo

18 Sin Fronteras. La detención migratoria: Un análisis desde el modelo penitenciario y el gasto público, CDMX, México, 2019. Human Rights Watch, Puertas cerradas: el fracaso de México en la protección de niños refugiados y migrantes de América Central, 31 de Marzo, 2016. En línea: https://www.hrw.org/es/report/2016/03/31/ puertas-cerradas/el-fracaso-de-mexico-en-la-proteccion-de-ninos-refugiados-y Global Detention Project. (2016). Anual Report 2016. En línea: https:// www.globalde-tentionproject.org/global-detention-project-an-nual-report-2016

19 Belattar, Abdelouahed. (2014). Menores migrantes no acompañados, Revista sobre la infancia y adolescencia, (7), España, 2014, p. 36.

20 Oficina de Naciones Unidas contra el Crimen y el Delito (ONUDD), Informe Mundial sobre la Tratad de Personas, Viena, 2016, p. 27. 
anterior, debido a que la discriminación se acentúa e influye en darles mayor riesgo a las niñas y las adolescentes quienes debido a ser víctimas de discriminación, se les reduce sus posibilidades de elección de vida y, por lo tanto, se sitúan en mayor vulnerabilidad a la trata.

Todos estos retos van sumando a la situación de vulnerabilidad, ya que ante este escenario facilita enormemente la labor de los tratantes y traficantes quienes hallan en la impunidad y la ausencia de instituciones sólidas su mejor aliado, convirtiendo de esta manera a este grupo poblacional en un blanco fácil y accesible, ya que carecen de la protección por parte del Estado, de sus progenitores y de cualquier adulto que ejerza la patria potestad.

Cabe señalar que no todas las víctimas de trata reúnen los elementos de la definición de refugiado, sin embargo; es indispensable que todos los NNA no acompañados y con indicios de protección internacional, entre ellos víctimas de trata tengan acceso al procedimiento de asilo.

Este argumento se refiere a que todos los NNA no acompañados deben ser "atendidos de acuerdo a los procedimientos y protocolos de atención existentes, los cuales tienen la finalidad de proteger la integridad, seguridad física, identidad y privacidad de los niños y las niñas de acuerdo a los estándares internacionales en materia de protección a las víctimas". ${ }^{21}$

\section{RETOS DE LOS NNA NO ACOMPAÑADOS PARA QUE ACCEDAN AL PROCEDIMIENTO DE ASILO}

Primero, es importante reconocer a México no sólo como un país con tradición migratoria, sino también como receptor de personas refugiadas, ya que en los últimos años se tienen registros importantes de números significativos de personas refugiadas, entre ellos NNA no acompañados. ${ }^{22}$

Hay que reconocer que después de la última elección presidencial de Estados Unidos ha provocado que México se convierta un país de destino para varias personas migrantes no sólo de Centroamérica sino también de otras regiones. ${ }^{23}$

21 Mier Hernández y Rodríguez Argüelles, La trata de niños, niñas: estado de la situación actual, Nova et Vétera, vol. 20, No 64, 2011, pp. 207-208

22 Arizpe, Lourdes. (2004). Los retos culturales de México. México. Miguel Ángel Porrúa, 2004, pp. 51-52.

23 Semple, Kirk. (2017, febrero) México: país de tránsito a nación refugio, Sección América Latina: México, The New York Times, 2017, En línea: https://www.nytimes.com/ es/2017/02/13/mexico-de-pais-de-transito-a-nacion-refugio/ 
Segundo lugar, tomando en cuenta lo anterior, "es sumamente importante identificar a un NNA no acompañado dentro de los flujos migratorios mixtos, independientemente si es candidato potencial a la condición de refugiado", ya que como lo mencionamos, debemos tener presente que tiene indicios de protección internacional. ${ }^{24}$

En tercer lugar, dependiendo del desarrollo mental y de madurez, debe de informarse a los NNA todos sus derechos, entre ellos, el derecho a recibir y solicitar asilo, el cual debe de contar con directrices para que el procedimiento de asilo sea accesible a favor de la niñez, particularmente de aquélla que no está acompañada.

Lo anterior, de conformidad con la Observación General No. 6 del Comité sobre Derechos del Niño, ${ }^{25}$ así como la observación conjunta ente el Comité sobre Derechos del Niño y Comité de Trabajadores Migratorios y de sus familiares de Naciones Unidas. ${ }^{26}$ Documentos que defienden que el procedimiento de asilo debe ser ajustado a las necesidades específicas de los NNA no acompañados.

Ahora bien, en caso que un NNA no acompañado no cuente con un grado de madurez suficiente, el ACNUR ha señalado que es necesario recurrir a factores objetivos, tales como las características del grupo población que el niño o la niña ha dejado, la situación que prevalece en el país de origen y la situación de los miembros de su familia, tanto dentro como fuera del país de origen. ${ }^{27}$ Lo anterior, es indispensable para que también el procedimiento de asilo sea posible y se ajuste a las necesidades específicas de todos los NNA no acompañados.

También, esto incluye que el NNA no acompañado debe ser informado que el DIF, mediante la Procuraduría de Protección a los Niños, Niñas y Adolescentes, quien será su asesor jurídico o representante legal y, además, le brindará la asistencia psicológica necesaria y le proveerá otros servicios que coadyuven a garantizar su derecho humano al asilo.

24 OIM, op., cit, p. 1 .

25 Comité de los Derechos del Niño. Observación General № 6, Trato de los menores no acompañados y separados de su familia fuera de su país de origen, CRC/GC/2005/6, 2005.

26 Comité de los Derechos del Niño, Comité sobre la Protección de los Derechos de Todos los Trabajadores Migratorios y de sus Familiares. Observación General conjunta No 4, las obligaciones de los Estados relativas a los derechos humanos de los niños en el contexto de la migración internacional en los países de origen, tránsito, destino y retorno, UN Doc. CMW/C/GC/4-CRC/C/GC/23, 2017.

27 ACNUR. Los niños refugiados: directrices sobre protección y cuidado, Ginebra, ACNUR, 1994, p. 6. 
En cuarto lugar, con el acceso al procedimiento de asilo, los NNA no acompañados con indicios de necesidades de protección se les debe brindar y garantizar todos sus derechos humanos, por lo tanto, deben recibir la misma protección que a cualquier otro niño o niña del país de acogida. Debido a que esta población se encuentra en desventaja porque está privada temporal o permanentemente de su medio familiar que vele por su interés superior. Por lo tanto, el Estado debe de proteger y garantizar todos y cada uno de sus derechos reconocidos por los instrumentos internacionales en materia de derechos humano.

En quinto lugar, los NNA no acompañados que accedan al procedimiento de asilo, el ACNUR ha señalado que "no deben ser detenidos por cuestiones de su estancia irregular, por lo tanto, no se les puede privar de su libertad". ${ }^{28} \mathrm{Si}$ bien es cierto que la Convención de 1951 sobre el Estatuto de los Refugiados no señala expresamente sobre la detención de NNA no acompañados con indicios de protección internacional, esta práctica no debería aplicarse en razón del sentido de la figura de asilo y de conformidad al enfoque de derechos humanos y los derechos de la infancia. ${ }^{29}$

Por lo tanto, el acceso al procedimiento de asilo a los NNA no acompañados protege y garantiza el principio de la no detención, que es acorde al principio del interés superior y del principio de no sanción por entrada irregular en el caso de los refugiados.

\section{ConClusión}

Actualmente, México se ha convertido en un país estratégico para las migraciones y para la política de asilo, debido a su posición geográfica y, además por las políticas restrictivas a la migración internacional por el actual presidente de Estados Unidos. Ante este contexto, México ha comenzado a tener diferentes flujos migratorios mixtos complejos. Entre ellos se encuentran una de las poblaciones en mayor situación de vulnerabilidad, es decir, los NNA no acompañados con indicios de protección internacional, quienes además de contar con una triple situación de vulneración: la edad, la condición de refugiado y la falta

28 ACNUR. Directrices del ACNUR sobre los criterios y estándares aplicables con respecto a la detención de solicitantes de asilo, Ginebra, ACNUR, 1999, p. 6.

29 Rea Granados, Sergio Alejandro, (2016b). Menores refugiados no acompañados en México: ¿Cómo proteger sus derechos y principios en caso de detención?, Revista Internacional de Derechos Humanos, (6), Argentina: Centro Latinoamericano de Derechos Humanos, 2016, p. 25. 
de documentos de estancia legal, enfrenta otros grandes desafíos para acceder al procedimiento de asilo.

Uno de los retos que observamos es que la falta de visibilización de este fenómeno social en México, lo cual tiene como consecuencia que los NNA no acompañados no accedan al procedimiento de asilo en México. De ahí la importancia de tomar en cuenta este problema para comenzar a identificar esta población y brindarles acceso a dicho procedimiento, ya que de lo contrario seguirán siendo sujetos de violaciones a sus derechos humanos.

También, durante este trabajo de investigación se pudo comprobar que no basta con contar con un procedimiento de asilo, sino que debe tener una perspectiva de género, de derechos humanos y sobre todo enfocados a proteger los derechos del niño(a), para que sea realmente efectivo y eficiente.

Por tal motivo, el procedimiento de asilo debe ser informado a los NNA no acompañados por las autoridades migratorias mexicanas $\mathrm{y}$ otros actores claves relevantes, quienes tienen la obligación internacional de proteger, respetar, defender y garantizar los derechos del niño(a).

Además, el acceso al procedimiento de asilo a los NNA no acompañados con indicios de protección internacional impide su detención y su retorno a su país de origen. Asimismo, permite restitución efectiva de sus derechos, asimismo les garantiza el derecho a la no devolución a su país de origen y la no sanción por su entrada irregular.

Por tal razón, se concluye que existen diversos obstáculos al acceso al procedimiento de asilo a favor de NNA no acompañados con indicios de protección internacional dentro de los flujos migratorios mixtos. Debido a la falta de acceso al procedimiento de asilo a esta población se atenta contra sus derechos humanos, así como a los derechos del niño(a) y sobre todo a los derechos de los refugiados.

\section{REFERENCIAS BILIOGRÁFICAS}

Alto Comisionado para los Derechos Humanos. (ACNUDH). (2014). Los derechos humanos y la trata de personas, Ginebra.

Alto Comisionado de las Naciones Unidas para los Refugiados. (ACNUR). (1994). Los niños refugiados: directrices sobre protección y cuidado, Ginebra, ACNUR. 
Alto Comisionado de las Naciones Unidas para los Refugiados. (ACNUR). (1999). Directrices del ACNUR sobre los criterios y estándares aplicables con respecto a la detención de solicitantes de asilo, Ginebra, ACNUR.

Alto Comisionado de las Naciones Unidas para los Refugiados. (ACNUR). (2016a). Directrices de elegibilidad para la evaluación de las necesidades de protección internacional de los solicitantes de asilo procedentes de Honduras, ACNUR, HCR/EG/HND/16/3.

Alto Comisionado de las Naciones Unidas para los Refugiados. (ACNUR). (2016b) Directrices de elegibilidad para la evaluación de las necesidades de protección internacional de los solicitantes de asilo procedentes de El Salvador, ACNUR, HCR/EG/SLV/16/1.

Arizpe, Lourdes. (2004). Los retos culturales de México, México. Miguel Ángel Porrúa.

Belattar, Abdelouahed. (2014). "Menores migrantes no acompañados", Revista sobre la infancia y adolescencia, (7), España.

Carbonell, Miguel. (2011). "Las obligaciones del Estado en el artículo 1ํㅜ de la Constitución Mexicana", en Miguel Carbonell y Pedro Salazar (eds.) La reforma Constitucional de Derechos Humanos: un nuevo paradigma, México, Instituto de Investigaciones Jurídicas de la UNAM.

Comisión Nacional de los Derechos Humanos. (CNDH). (2016). Orientaciones para las Áreas Especializadas en los Derechos de Niñas, Niños y Adolescentes de los Organismos Públicos de Derechos Humanos, CNDH, UNICEF

Comisión Interamericana de Derechos Humanos. (CIDH). (2013). Derechos humanos de los migrantes y otras personas en el contexto de la movilidad humana en México, OEA/Ser. L/V/II, Washington, D.C.

Comité de los Derechos del Niño. (2005). Observación General № 6, Trato de los menores no acompañados y separados de su familia fuera de su país de origen, $\mathrm{CRC} / \mathrm{GC} / 2005 / 6$.

Comité de los Derechos del Niño, Comité sobre la Protección de los Derechos de Todos los Trabajadores Migratorios y de sus Familiares (2017). Observación General conjunta No 4, las obligaciones de los Estados relativas a los derechos humanos de los niños en el contexto de la migración internacional en los países de origen, tránsito, destino y retorno, UN Doc. $\mathrm{CMW} / \mathrm{C} / \mathrm{GC} / 4-\mathrm{CRC} / \mathrm{C} / \mathrm{GC} / 23$.

Desarrollo Integral de la Familia Nacional. (DIFNacional). (2014). Unidad de Enlace, Descripción e Informe de Resultados. Programa para la Protección y el Desarrollo Integral de la Infancia, Consultado en http://www.dif. gob.mx/diftransparencia/media/DGPI-InformResultadosEne-Dic2014. pdf

Global Detention Project (2016). Anual Report 2016. En línea: https:// www.globalde-tentionproject.org/global-detention-project-an-nual-report-2016 
Human Rights Watch. (2016). Puertas cerradas: el fracaso de México en la protección de niños refugiados y migrantes de América Central, Consultado en https://www.hrw.org/es/report/2016/03/31/puertas-cerradas/ el-fracaso-de-mexico-en-la-proteccion-de-ninos-refugiados-y

Mier Hernández y Rodríguez Argüelles. (2011). "La trata de niños, niñas: estado de la situación actual". Nova et Vétera, 20(64).

Oficina de Naciones Unidas contra el Crimen y el Delito (ONUDD). (2016). Informe Mundial sobre la Trata de Personas, Viena.

Organización Internacional para Las Migraciones (OIM). (2009). Migración Irregular y los Flujos Migratorios Mixtos: Enfoque de la OIM, MC/ INF/297.

Ortega Velázquez, Elisa. (2015). "Los niños migrantes irregulares y sus derechos humanos en la práctica europea y americana: entre el control y la protección". Boletín mexicano de derecho comparado, 48(142).

Rea Granados, Sergio Alejandro. (2016a). "Retos Actuales en la Implementación de la Ley sobre Refugiados y Protección Complementaria en México: Identificación, Admisión y Acceso al Procedimiento de Asilo", Anuario Mexicano de Derecho Internacional, (XVI), México, Instituto de Investigaciones Jurídicas, UNAM.

Rea Granados, Sergio Alejandro. (2016b). "Menores refugiados no acompañados en México: ¿Cómo proteger sus derechos y principios en caso de detención?", Revista Internacional de Derechos Humanos, (6), Argentina: Centro Latinoamericano de Derechos Humanos.

Semple, Kirk. (2017). México: país de tránsito a nación refugio, Sección América Latina: México, The New York Times. Consultado en https://www. nytimes.com/es/2017/02/13/mexico-de-pais-de-transito-a-nacion-refugio/

Sin Fronteras. (2019). La detención migratoria: Un análisis desde el modelo penitenciario y el gasto público, CDMX, México.

The World Bank. (2011). Migration and Remittances Factbook 2011, Washington $\mathrm{D}, \mathrm{C}$.

UNHCR. (2014). Children on the Run: Unaccompanied Children Leaving Central America and Mexico and the need for International Protection.

\section{RESUMEN CURRICULAR DEL AUTOR}

Sergio Alejandro Rea Granados

Doctorando en Derecho, Universidad de Chile, Santiago. Master of Public and International Law, Universidad de Melbourne, Australia. 
Licenciado en Derecho, Universidad Iberoamericana, Ciudad de México. Artículo de investigación, financiado por la Comisión Nacional de Investigación Científica y Tecnológica, CONICYT-PCHA/Doctorado Nacional/2016-21160698. https://orcid.org/0000-0003-2672-8676 Dirección electrónica: rea_sergio@hotmail.com 